\title{
Electrochemical Determination of Diclofenac Sodium in Pharmaceutical Sample Using Copper Nanoparticles/Reduced Graphene Oxide Modified Glassy Carbon Electrode
}

\author{
Haichi Yu*, Jianhang Jiao, Qiuju Li, Yingzhi Li \\ Department of Orthopaedics, The Second Hospital of Jilin University, Changchun, 300041, China \\ *E-mail: liyingzhi2014@126.com
}

Received: 29 May 2021/ Accepted: 27 July 2021 / Published: 10 September 2021

\begin{abstract}
This study presents electrochemical determination of diclofenac sodium (DCS) in a pharmaceutical sample using copper nanoparticles reduced graphene oxide hybrid electrodes ( $\mathrm{Cu} \mathrm{NPs} / \mathrm{rGO}$ ). rGOnanosheets were synthesized on a glassy carbon electrode (GCE) by modified Hummers method, and then, $\mathrm{Cu}$ NPs were electrodeposited on $\mathrm{rGO} / \mathrm{GCE}$. Results of structure and morphology studies by SEM and XRD revealed that the irregular $\mathrm{Cu}$ NPs electrodeposited in crystal structure with approximately $130 \mathrm{~nm}$ diameter. Electrochemical analyses using the $\mathrm{CV}$ technique showed that $\mathrm{Cu}$ $\mathrm{NPs} / \mathrm{rGO} / \mathrm{GCE}$ exhibited a higher sensitivity for determination of DCS than that GCE, rGO/GCE and $\mathrm{Cu}$ NPs/GCE due to synergetic effect of $\mathrm{Cu}$ NPs and rGO which facilitates the electron transfer between the electrode and the electroactive species in solution and improve electrocatalytic oxidation of DCS. Amperometry measurements on $\mathrm{Cu} \mathrm{NPs} / \mathrm{rGO} / \mathrm{GCE}$ as DCS sensor showed that linear range, limit of detection and sensitivity were obtained 20 to $400 \mu \mathrm{M}, 8 \mathrm{nM}$ and $0.0356 \mu \mathrm{A} / \mu \mathrm{M}$, respectively. The applicability of $\mathrm{Cu}$ NPs/rGO/GCE to determine DCS concentration in the prepared real pharmaceutical sample was examined and results showed that recovery $(\geq 97.66 \%)$ and RSD $(\leq 3.05 \%)$ values were acceptable and this method provided suitable precision and accuracy for practical analyses in the pharmaceutical samples using $\mathrm{Cu}$ NPs/rGO/GCE.
\end{abstract}

Keywords: Diclofenac Sodium; Electrodeposition; Copper Nanoparticles; Reduced Graphene Oxide; Amperomety

\section{$\underline{\text { FULL TEXT }}$}

(C) 2021 The Authors. Published by ESG (www.electrochemsci.org). This article is an open access article distributed under the terms and conditions of the Creative Commons Attribution license (http://creativecommons.org/licenses/by/4.0/). 